\title{
A questão da Academia de Direito com os Frades Franciscanos
}

Pablicamos a seguir, precedido das notas tachygraphicas dos actos dos Ministros Julgadores, o ACCORDAM que em 9 de abril do corrente anno proferiu a Côrte Suprema, dando ganho de causa á Faculdade, na acção contra ella intentada pela Provincia Franciscana da Immaculada Conceição, a proposito do dominio do terreno onde se acha o edificio da Escola.

A auctora havia vencido o pleito em primeira instancia. Em grau de appellação, a Côrte Suprema reformou a sentença appellada.

Reconhecendo com o dr. juiz A QUO a propriedade da acção proposta (Nunciação de Obra Nova), repellindo com elle a invocada illegitimidade de parte e com elle acceitando varios dos argumentos em que estribou sua sentença, a Côrte todavia cassou o julgado, declarando preseripta a acção e, por via de consequencia, improcedente o pedido.

Foi a prescripção o fundamento unico de decidir; a prescripção acquisitiva (usucapião) e não a extinctiva quinquennal.

Ha muitos annos, na acção de esbulho que moveu eontra Frei Basilio Romen e outros, a Fazenda Nacional manifestou de modo claro e categorico que requisitava o edificio da Faculdade como do dominio publico e que assim - possuia, com intenção de senhor - ANIMUS DOMINI.

Dahi começou a correr o prazo da prescripção acquisitiva, isto é, o lapso dentro do qual deviam os Franciscanos reagir contra essa pretenção, reivindicando em juizo a propriedade do immovel e impedindo por esse unico meio que a posse da Fazenda convalescesse em dominio pela diuturnidade do tempo. 
Como não o houvessem feito, consummou-se a usucapião; consummada a usucapião a beneficio da Faculdade, extinguiu-se obliquamente a acção que tinham para vimdicar o terreno.

Dahi o julgado, na fórma em que foi proferido.

Eis as notas tachygraphicas e accordam:

\title{
NOTAS TACHYGRAPHICAS
}

\section{APPELlAÇÃO CIVEL N: ${ }^{\circ}$ 6.526 - SAO PAULO}

\author{
Relator: o sr. Ministro Octavio Kelly \\ Appellantes: $10^{0}-0$ Juiz Federal "ex-officio"; $2^{a}$ - União Federal; \\ $3 .^{a}$ - a Faculdade de Direito de São Paulo \\ Appellada: Provincia Franciscana da Immaculada Conceição do \\ Rio de Janeiro
}

\section{RELA T OR I O}

O sr. Ministro Octavio Kelly - A Provincia Franciscana da Immaculada Conceição do Rio de Janeiro propoz contra a Fazenda Nacional e a Faculdade de Direito de São Paulo uma acção de embargo de obra nova perante o Juizo Federal da Secção de São Paulo, allegando:

a) que, por titulos seculares, é proprietaria do predio e terreno do Convento de São Francisco, onde se acham a Egreja de seu nome e a Faculdade de Direito, na capital do Estado; que em 1828 cedeu ao Governo Imperial parte do immovel para nelle funccionar o curso juridico; b) que, não obstante a precariedade da cessão, a Faculdade fez obras no edificio, estendendo-se sobre terreno em que não lhe fôra concedido uso algum e perturbando o em que se acham alojados os membros componentes da Ordem; c) que, em 1932, a requerente fez notificar aos reus que não permittia a execução das obras e considerava extincto o uso concebido em 1828, mas, a despeito disso, ellas proseguiram, levando o nunciante a embargal-as por acto judicial. Na 
contestação dizem os reus: a) que a nunciante é parte illegitima, uma vez que o edificio da Faculdade, antes de passar ao dominio nacional, estava na posse dos Menores Observantes da Provincia da Conceição, que se extinguiu não se transmittindo os bens á Provincia ora accionante; b) que as obras se executam exclusivamente no predio e jardim interno, onde os reus teem posse titulada e publica, ha mais de cem annos, animo domini; c) que as obras em nada perturbam o uso regular da parte do edificio occupado pelos Frades; d) que estão prescriptas quaesquer acções contra a Fazenda Nacional quanto ao immovel incorporado ao patrimonio da Nação com o consentimento dos Menores Observantes da Provincia da Conceição.

O Juiz proferiu a sentença de fls. 276 a 286 . E fêl-o deixando assentados os seguintes pontos:

1..$^{\circ}$ - que a Provincia auctora é successora da dos Menores Observantes, e o seu actual provincial o representante legitimo da Ordem; $2 .^{\circ}$ ) - que é competente $a_{\text {n nun- }}$ cíação da obra nova, ainda que o nunciante a embargue em solo da sua propriedade e não se trate de servidão entre predios; $3 .^{\circ}$ ) — que o titulo dos reus decorre de uma cessão feita em 1828 de direito real do uso, como, a respeito, estão de accordo as partes da lide; $4 .^{\circ}$ ) - que o dominio da nunciante provém do decreto de 16 de setembro de 1917, que a auctorizou a conservar e possuir os bens de que fosse titular, e como corporação de mão morta sómente tinha limites o seu poder de alienar; 5. $)$ - que, cedendo ao governo o uso de parte do Convento em 1828, não se despojou do dominio; $\left.60^{\circ}\right)$ - que as rés não poderiam mudar o titulo por que possuiam, ainda que fosse por um seculo; $7 .^{\circ}$ ) - que, como usuario, o Estado sómente tinha a posse directa, insuscepetivel de ser convertida em titulo de dominio no regimen anterior ao Codigo Civil; $8^{\circ}$ ) - que a possessoria intentada em 1910 não poderia importar contradição capaz de conduzir a esse objectivo, uma vez que a intervenção foi logo contestada pela parte, excluindo a hypothese de pretendida 
transformação; 9.0) - que, depois do Codigo Civil, antes da obra ser embargada, acto algum se registra revelando opposição dos reus ao dominio da nunciante, que désse nascimento á posse apta a geral-o por usucapião, ou ao perecimento do direito da reivindicação contra a Fazenda (Codigo Civil artigo 178, $\S 10 \mathrm{n}$. VI).

Com esses fundamentos, julgou procedente o pedido de demolição da obra, que tinha por offensiva do uso regular do trecho do Convento, em que a Communidade auctora se acha installada, condemnados ainda os reus nas custas do feito.

Da decisão appellaram o juiz ex-officio, a União Federal e a Faculdade de Direito, arrazoando as partes a fls. 295, 304 e 314. Suistentam os recorrentes:

a) que no regimen imperial as ordens monasticas eram, quanto aos bens, méras detentoras, administradoras e usufructuarias de um patrimonio cujo dominio directo pertencia ao Estado (Ferr. Alves - Constituição das Leis da Prov. p. trezentos e quarenta e cinco; Ruy Barbosa - Parecer p.; A. Bernardes - cit. na Epanaphora Jurid. de C. de Oliveira p. 15; Ord. do Thes. numero 81.053 e 417 e 436.865);

b) que a Ord. do L. II Tit. 18, vigente no Imperio por força de lei de 20 de Outubro de 1823, determinava que nenhuma Ordem pudesse adquirir ou possuir sem licença do Rei, e adquirindo-se contra dicta defesa, os bens se perdessem para a Corôa;

c) que a consulta da Mesa da Consciencia e Ordens de 4 de Setembro de 1827 affirma que o solo do Brasil nunca foi das Ordens nem de suas egrejas (Col. de leis de 1827);

d) que os avisos e leis desse tempo e posteriores sempre reconheceram sómente assistir a essas instituições o direito utendi e fruendi, que é annexo á obrigação de encargos (Av. n. 172 de 27 de outubro de 1828, e n. 143 de 15 de abril de 1834, Ord, do Thes. n. ${ }^{\circ} 56$ de 1853);

e) que a lei n. 1764 , de 1870, consultando ás finalidades das leis de amortização mandou que no prazo de dez annos 
se convertessem, em titulos intransferiveis, os bens que as ordens religiosas possuiam, preceito ainda affirmado no Regulamento n..$^{\circ} 9094$ de 1883, que apenas excluiu os conventos e dependencias residenciaes de trez ou mais religiosos professos (artigo $16 \& 10^{\circ}$ combinado com o artigo $10^{\circ} \mathrm{n} .^{\circ} 1$ );

f) que, por solicitação do director dos Cursos Juridicos, em 1828, dirigiu-se o ministro do Imperio ao Provincial da Ordem Terceira de São Francisco, indagando da inconveniencia da cessão do Convento para os serviços do ensino, e, em resposta, o representante da communidade, declarando que esta nada possuia proprio e quanto ao goso só o tinha devido á piedade dos povos, acquiesceu na entrega, que se tornou effectiva, ao Almoxarife da Fazenda Nacional em São Paulo, a 3 de Dezembro de 1828 (fls. 135);

g) que o governo sempre se julgou senhor e possuidor do Convento, quanto á parte cedida para os serviços da Faculdade de Direito, fazendo-lhe concertos e defendendo-a na acção do esbulho intentada contra frei Romeu em 1910;

h) que, tendo sido as obras embargadas, effectuadas nessa parte, de incontestavel dominio das rés, força é confessar que improcede a acção, que a justificar nem mesmo tem o prejuizo de qualquer servidão tutelada pelo direito civil;

i) que se direito assistisse á auctora á reivindicação desse immovel, estaria prescripto pelo decurso de cinco annos a partir de formal contestação da Fazenda Nacional na acção do esbulho, definitivamente julgada em 1918.

Essas razões foram impugnadas pela auctora, que desenvolveu os argumentos já expedidos na inicial e reproduzidos nas allegações finaes.

\section{VOTO}

Bem decidiu a sentença appellada repellindo as preliminares de illegitimidade da parte e impropriedade da acção. A actual Provincia Franciscana da Immaculada Conceição 
do Rio de Janeiro é a mesma instituição que, conhecida tambem pela denominação particular de Menores Observantes, oedera em 1828 o Convento de São Francisco, em São Paulo, para, no respectivo edificio, funccionar o Curso Juridico installado nessa cidade, e o outorgante do mandato de fl. 9 é o auctorizado representante da Ordem accionante. Assistia-lhe, portanto, qualidade para examinar o alcance da relação de direito resultante da cessão do immovel e de agitar a questão relativa ao pretendido dominio no pleito intentado contra os appellantes. Tambem não soffre contestação a idoneidade do meio judicial invocado, $e x$-vi de nova preceituação, a respeito, contida no artigo 573 do Codigo Civil.

Merece, porém, reforma o mesmo julgado na parte que repelliu a arguida prescripção invocada pela União a fls. 270 das allegações finaes. Com a propositura da acção do esbulho, em cuja inicial a União Federal se confessava proprietaria de toda a parte do Convento occupada pelos serviços da Faculdade de Direito, essa litigante denunciou ao publico, com sciencia da appellada, o seu animus domini sobre o questionado immovel. Dahi começaria a correr o prazo de prescripção da acção que pudesse caber á appellada para contestar-lhe esse dominio e reivindicar a coisa. Allega-se que a decisão do Supremo Tribunal não déra ganho de causa á Fazenda e desse pronunciamento se pretende concluir que a Justiça reconhecera á Ordem Franciscana a propriedade de parte, então, ha quasi um seculo, occupada pelas appellantes. $O$ exame do accordam, entretanto, mostra quão forçada é a conclusão que de seus termos se pretende tirar.

De facto, a União decahiu da acção, mas o seu insuccesso, tratando-se de uma causa possessoria, foi devido, simplesmente, a ter a justiça apurado que os commodos occupados pelos frades franciscanos, unidos á parte do edificio em que funcciona a Faculdade, nunca foram utilizados para os seus serviços, circumstancias que excluiram a posse 
das appellantès, cuja genese e fundamento repousaram nas necessidades do Curso Juridico. Mas ainda quando a invocação dessa posse, como elemento exterior ou manifestação do dominio pudesse a appellada invocar com apoio no julgado que lhe deu ganho de causa, ella estaria circumscripta aos aposentos occupados pelos frades e de que a Faculdade de Direito nunca se utilizara.

O certo, porém, é que, consentindo na destinação do immovel para um serviço publico do Imperio, sob cujas leis viviam em manifesta dependencia as Ordens regulares religiosas, os Menores Observantes e a Congregação em que estes se transformaram - a Provincia Franciscana - demittiram de si, a titulo definitivo, a posse que mantinham sobre o referido edificio, do qual a administração official se apropriou, usando como seu, fazendo-lhe obras, adaptandoo ás exigencias do ensino, excluindo-o de tributos, como bem publico que ficára sendo, resultante de uma cessão, que outra coisa não era senão uma transferencia de caracter permanente, uma vez que nada se pactuara a respeito da sua restituição aos cedentes, por effeito de decurso de certo prazo ou de evento de dada condição. E a Fazenda tanto assim vinha entendendo que, ao se constituir o patrimonio autonomo dos institutos officiaes do ensino, entregou a $\mathrm{Fa}$ culdade de Direito de São Paulo, entre outros bens, o proprîo edificio, cuja propriedade tão tardiamente se contesta nesta lide.

Meu voto, é, portanto, para, reformando a sentença de primeira instancia, julgar prescripta a acção da auctora para o reconhecimento de qualquer direito de dominio, quanto ao edificio da Faculdade de Direito, prescripção que se teria completado em favor da União, de quem a mesma Faculdade houve o immovel por disposição regular, e á qual teria de responder pela legitimidade da transferencia, se titular não fosse, ao seu tempo, do dominio de que se.despojou para a constituição do patrimonio do referido instituto. Não poderia, conseguintemente, a appellada, com funda- 
mento no questionado dominio do immovel, impedir que a sua actual proprietaria nelle edificasse, como lhe approuvesse, desde que, com isso, não offendia como não offendeu, qualquer servidão de vizinhança, uma vez que, fazendo as obras embargadas, observadas foram as regras que a respeito institue o Codigo Civil. E porque não lhe assiste esse direito, de meritis tenho o pedido por improcedente, mandando que o embargo seja suspenso e se prosiga nas obras.

O sr. Ministro Ataulpho de Paiva - A nunciante Provincia Franciscana da Immaculada Conceição do Rio de Janeiro, nos autos de nunciação de obra nova que promoveu e em que são nunciadas a Fazenda Nacional e a Faculdade de Direito de São Paulo, obtendo embargo nas obras que esta estava executando, allegou em seus artigos: que ella nunciante é, por titulos seculares, proprietaria do predio e terreno onde se acham, na Capital do Estado de São Paulo - o Convento e Egreja de São Francisco e a Faculdade de Direito; que em 1828 concedeu ao Governo do Imperio, a titulo precario e gratuitamente, o uso da parte do convento, onde desde então começou a funccionar e presentemente ainda funcciona a Faculdade de Direito de São Paulo; que, ha alguns annos, entrou ella em negociações com os nunciados para transferencia a estes da propriedade daquella parte do Convento, não chegando, porém, á conclusão satisfactoria, devido a desaccordo fundamental, a respeito da divisão da parte do predio que confina com a Egreja de São Francisco; que, não obstante o titulo precario em virtude do qual se acha installada no predio a Faculdade de Direito de São Paulo, entendeu esta de fazer obras no edificio que o alteram profundamente e que se extendem por terreno da Nunciante, os quaes até agora estavam desoccupados e sobre os quaes aquella Faculdade não tinha concessão de uso, accrescendo que algumas dessas obras irão perturbar o uso regular de um trecho do Convento onde se acham alojados os frades da Communidade; que, em abril de 1932, ella 
Nunciante notificou aos Nunciados que não só considerava extincta a cessão de uso do predio onde funcciona a Faculdade de Direito, como não permittiria a execução de obras naquelle predio sem a sua approvação prévia; que, a despeito dessa notificação e dos factos anteriores, os Nunciados persistem em executar obras de grande vulto no predio, as quaes ainda não se acham terminadas, esquecidos de que o direito de propriedade da Nunciante já foi reconhecido, em dois Accórdams do Supremo Tribunal Federal em um dos quaes se lê textualmente o seguinte: "Como se vê pelo aviso de 28 de Agosto de 1828 (fls. 375) dirigido pelo Ministro José Clemente Pereira ao primeiro Director do Curso Juridico, General José Arouche de Toledo Rendon, os Frades cederam o uso do Convento e cederam gratuitamente sem nenhuma recompensa"; que, constituindo essas obras, como constituem, offensa á propriedade da Nunciante, os artigos devem ser recebidos e julgados provados afim de os Nunciados serem condemnados a abandonar a obra que deliberaram executar, demolindo as que ja fizeram, de modo que se restitua tudo ao antigo estado, e a pagar as custas do processo:

Contestando, dizem as Nunciadas que a Nunciante não é parte legitima para intentar a acção, porque o edificio onde funcciona a Faculdade, antes de passar para o dominio da Fazenda Nacional, estava na posse dos Menores Observantes da Provincia da Conceição que se extinguiu, não se transmitindo á Nunciante os seus direitos; que as obras se excutam exclusivamente no predio outróra dos Menores Observantes e no jardim interno, onde as Nunciadas teem posse ha mais de cem annos, titulada, publica, mansa e pacifica (animo domini) sem qualquer reclamação da Nunciante; que as obras em nada podem perturbar o uso regular da parte do edificio em que se acham alojados os Frades; que o Convento foi incorporado em 1828 por acto do Governo Imperial e com o consentimento da Ordem dos Menores Observantes da Provincia da Conceição, como proprio nacio- 
nal, e não somente com o direito de uso; que cedendo a Ordem o uso do Convento, cedeu tudo o que tinha no immovel; que as negociações entre a Faculdade de Direito e a Nunciante sempre tiveram o caracter de méra transacção para remover o incommodo resultante de estar uma parte do edificio occupada em planos differentes pela Faculdade e pela Nunciante, sem o reconhecimento do direito desta, para o que nem tinha aquella os poderes necessarios; que essas negociações foram interrompidas quando ao conhecimento da Congregação da Faculdade chegaram documentos que excluem qualquer duvida sobre o dominio da União; que, finalmente, estão prescriptas quaesquer acções contra a Fazenda Nacional quanto ao immovel que ella possue como dona ha mais de cem annos, com justo titulo.

A requerimento da Nunciante, antes da dilação probatoria, procedeu-se a uma vistoria do immovel, para perpetuação (fls. 72). Durante a dilação prestaram seus depoimentos pessoaes Frei Diogo de Freitas, representente da Nunciante Auctora, e o Doutor José de Alcantra Machado de Oliveira, Director da Faculdade de Direito de São Paulo (fls. 93 e 94). Inquiriram-se testemunhas das Nunciadas (fls. 112), procedendo-se á nova vistoria a requerimento das Rés (fls. 104, 170 e 174), as quaes offereceram na prorogação impetrada as certidões de fls. 128 e seguintes contendo: a petição inicial na acção de esbulho intentada pela Fazenda Nacional contra Frei Basilio Rower e outros; o officio de 9 de Dezembro de 1828 do Director do Curso Juridico José Arouche de Toledo Rendon ao Ministro do Imperio José Clemente Pereira sobre diversas providencias que tomara para a occupação do edificio; um officio de 23 de Setembro de 1829 de Frei José de Santa Delphina, guardião do Convento de São Luiz á Camara Municipal de Itú; o inventario dos bens do Convento a que procedeu o Almoxarife da Fazenda Nacional; a portaria de 13 de Agosto de 1828, em que o Ministro do Imperio pede ao Provincial dos Menores Observantes da Provincia da Conceição o uso de todo o Con- 
vento para o Curso Juridico da Cidade de São Paulo; a de 20 do mesmo mez communicando que Sua Majestade Imperial louva e acceita a cessão determinando que o Convento seja entregue ao Director dos estudos e a Egreja á Ordem Terceira; a de 27 de outubro do mesmo anno sobre a remoção dos moveis e alfaias pertencentes aos Frades; uma ordem da Mesa Definitorial ao padre Guardião do Convento sobre o mesmo assumpto; a portaria de 21 de Agosto de 1828, participando ao Vice-Presidente da Provincia de São Paulo as determinações do Governo Imperial para que este as fizesse constar á Ordem Terceira; a resposta do Provincial dos Menores Observantes á portaria de 13 de Agosto de 1828, datada de 16; o officio de 12 de Setembro de 1828, do VicePresidente da Provincia communicando á Mesa da Ordem Terceira de São Francisco as determinações da portaria de 21 de Agosto; o officio de 14 de Novembro do mesmo anno, do Vice-Presidente da Provincia ao Guardião sobre a entrega do Convento e o do Guardião datado da vespera.

Depois de arrazoada a causa pelas partes, foi proferida a sentença final de fls. 276 v., na qual, após longas considerações, concluiu o Juiz julgando procedente o pedido para condemnar, como condemnou as Nunciadas a demolirem a obra emprehendida no Convento da Nunciante, repondo tudo no anterior estado em que se achava. As Nunciadas appellaram dessa decisão (termo a fls. 299). Nesta instancia superior arrazoaram ambas as partes, tendo o sr. Procurador Geral, então o sr. Ministro Bento de Faria, em seu parecer de fls. 295, opinado pela improcedencia da acção.

De todo procedentes, a meu ver, as razões em que as Nunciadas defenderam o seu direito, maximé na parte em que, de accordo com o sr. Dr. Procurador Geral, sustentam a impropriedade da acção proposta. Ninguem nega e antes é uma verdade bem definida e conceituada, que o remedio de embargo de obra nova, constituindo postulado juridico que se origina da legislação romana, encontrou nos nossos 
codigos legislativos a mais ampla e perfeita divulgação e effectividade.

Tem logar o embargo de obra nova, quando alguem construe obra nova que prejudique a servidão de outrem (Decreto n. $^{\circ} 3.084$ de 5 de Novembro de 1898 - artigo 415 Parte terceira. Decreto n. $^{\circ} \mathbf{7 7 3}$ de 19 de Setembro de 1890 Artigo $10^{\circ} \S$ unico). O proprietario pode embargar a construcção de predios que invada a área do seu, ou sobre este deite gotteira, bem como a daquelle, em que, a menos de metro e meio do seu, se abra janella ou se faça eirado ou varanda (Codigo Civil - artigo 573). Condições, porém, bem precisas e assignaladas, conforme as licções da jurisprudencia, se exigem para que essa providencia legal possa ser concedida e applicada. Entre ellas, mistér é que a materialidade do facto impugnado esteja devidamente comprovada, tal como a lei o descreve para permittir o recurso immediato.

Ora, a Nunciante requereu e obiteve o embargo das obras que a Faculdade de Direito de São Paulo estava fazendo na área da sua posse, em cujo goso se achava ha mais de cem annos, allegando que taes obras prejudicavam a residencia della Nunciante, privando-a do uso regular do edificio em que a Communidade se acha installada e bem assim a saude dos seus congregados.

Conseguiu, porém, provar a sua intenção e o facto articulado? Conseguiu provar, como quer a expressa disposição do Codigo Civil, que as obras embargadas invadiram ou invadiriam a área da Egreja de São Francisco por ella possuida? se sobre essa área deita gotteira, ou se a menos metro e meio das paredes externas desse templo tenham sido abertas janellas ou feito eirado, terraço ou varanda?

Difficil não é a resposta pela negativa, á vista dos termos das vistorias procedidas, onde averiguado ficou que a edificação projectada e em execução fica a mais de quatro metros e meio da parede externa da Nunciante; que não 
deita gotteiras sobre o predio e que pode a obra ser realisada sem prejuizo da segurança deste.

Falharam, por conseguinte, os principaes motivos que auctorizariam a regularidade e propriedade da ącção qual a Nunciante se arroga com direito, aliás bem contestavel, em importantes pontos de vista, mas sou naturalmente levado a restringir-me em considerações, por ter limitado o meu voto como ficou dito e ora faço, circumstancia de pronuncial-o com o fito directo de julgar improcedente, repito, pela sua impropriedade, a acção proposta.

E' o meu voto.

O sr. Ministro Eduardo Espinola - Parece-me bem justificada na sentença appellada a propriedade de nunciação de obra nova para o caso sub-judice.

Quanto ao merito são dignos de consideração os argumentos expendidos pela longa e minuciosa decisão do illustre dr. Juiz a quo em varios pontos.

Diz, entretanto, que, no caso, não é possivel fallar em usucapião.

Não me parece.

Tem a União a posse antiquissima, de mais de cem annos.

A propria sentença reconhece que a União na acção possessoria de 1910, tendo-se declarado proprietaria do immovel, transferiu o seu direito para o patrimonio da Faculdade de São Paulo. Voto de accordo com o sr. Ministro Relator.

Deram provimento ás appellações para julgar prescripta a acção da "autora nunciante", contra o voto do sr. Ministro Ataulpho de Paiva, que dava provimento para julgar improcedente a acção, por impropriedade da mesma. Impedido, o sr. Ministro Bento de Faria.

\section{ACCORDAM}

Vistos, relatados e discutidos estes autos de acção ordinaria, entre partes, appellantes - "ex-officio" o Juiz Sec- 
cional de São Paulo, a União Federal e a Faculdade de Direito de São Paulo, appellada a Provincia Franciscana da Immaculada Conceição do Rio de Janeiro, accordam em maioria os Ministros da Côrte Suprema, constituidos em turma julgadora, pelas razões e fundamentos constantes das notas tachygraphicas que precedem, dar provimento ás appellações para julgarem prescripta a acção intentada. Custas como de lei. Districto Federal, 9 de abril de 1937 (data do julgamento).

E. Lins, Presidente

Octavio Kelly, Relator 